\title{
How Long Can Joint Position Sense Be Retained in Memory by Young Healthy Subjects?
}

\author{
Di Xie ${ }^{1)^{*}}$, Yukio Urabe ${ }^{2)}$ \\ 1) Institute of Sports Medicine, Taishan Medical University: Changcheng Road 619, Taian city, \\ Shandong Province 271000, China \\ 2) Department of Sports Rehabilitation, Graduate School of Health Sciences, Hiroshima University, \\ Japan
}

\begin{abstract}
Purpose] The aim of the present study was to investigate how long joint position sense (JPS) can be retained in memory. [Subjects] Eleven healthy subjects (5 men and 6 women) were enrolled in this study. [Methods] Subjects memorized a specific joint position visually, and then they were asked to reproduce without visual aid the position at 3 different time intervals: immediately, 5 minutes post-memorization, and 30 minutes post-memorization. [Results] Differences in JPS between time intervals of immediate and 30 minutes post-memorization were statistically significant with the exception of knee flexion at $60^{\circ}$ with a $5 \mathrm{~kg}$ load. Differences in reproduced JPS between time intervals of immediately and 5 minutes post-memorization were not statistically significant. [Conclusions] The results suggest that JPS can be retained in memory for approximately 5 minutes.

Key words: Joint position sense, Memory, Retain
\end{abstract}

(This article was submitted Jun. 24, 2013, and was accepted Jul. 22, 2013)

\section{INTRODUCTION}

Joint position sense (JPS) is generally defined as the ability to assess a limb's relative position in space, without the assistance of vision. This skill is very important for athletes in sports such as alpine skiing and snowboarding. It is believed that high-level athletes demonstrate good JPS ${ }^{1)}$. At the opposite end of the spectrum, abnormal JPS has been reported to be associated with a number of knee disorders such as knee joint osteoarthritis ${ }^{2)}$, patellofemoral pain syndrome $^{3)}$, and anterior cruciate instability ${ }^{4}$. JPS cannot be judged appropriately if the measurement methodology is less than ideal.

Many types of evaluation methods for JPS are used in clinical practice. In general, position sense is more accurate when measured under active conditions than passive conditions, because the brain is able to obtain more input signals from the surrounding environment ${ }^{5}$. In active movements, there is a greater level of peripheral afferent information generated and received. This results in quicker and more accurate reproduction of JPS.

Borsa et al. concluded that, in the presence of limb deficiencies, positional proprioception is significantly more sensitive at the end ranges of knee extension, and is also significantly more sensitive as the limb is moved in the di-

*Corresponding author. Di Xie (e-mail: ditianxie@hotmail.

com)

(C)2014 The Society of Physical Therapy Science

This is an open-access article distributed under the terms of the Creative Commons Attribution Non-Commercial No Derivatives (by-ncnd) License $<$ http://creativecommons.org/licenses/by-nc-nd/3.0/>. rection of extension ${ }^{6}$. Additionally, muscle activity may play an important role in JPS due to the relation between JPS and muscle spindle activity ${ }^{7,8}$. Joint load influences JPS by increasing muscle activity. Previous studies have investigated the correlation between muscular strength and proprioception, and have reported the presence of a positive correlation between JPS and quadriceps strength ${ }^{9}$. In consideration of these factors, we decided that JPS should be measured in an active condition, with proper load and optimum joint angle.

JPS is influenced by many factors, as it is governed by both central and peripheral nervous system mechanisms, chiefly via muscular receptors as well as tendinous, articular, and cutaneous receptors ${ }^{10)}$. Currently, many aspects of the influence of the central nervous system on JPS are unknown. During JPS measurement, subjects must memorize joint position and then reproduce it. However, it remains unclear as to whether JPS memory can be sustained after initial JPS is measured. The aim of this study was to investigate how long JPS can be retained in memory and to clarify the influence of joint angle and load on JPS memory. The original hypothesis of this study postulated that JPS can be retained in memory for 5 minutes and that joint angle and load were likely to influence JPS memory.

\section{SUBJECTS AND METHODS}

\section{Subjects}

Eleven healthy subjects (5 men and 6 women) with a mean age of $26.0 \pm 2.3 \mathrm{y}$, having a mean body weight of $60.2 \pm 16.4 \mathrm{~kg}$, and a mean height of $166.1 \pm 10.1 \mathrm{~cm}$ participated in this study. Subjects who reported the presence 


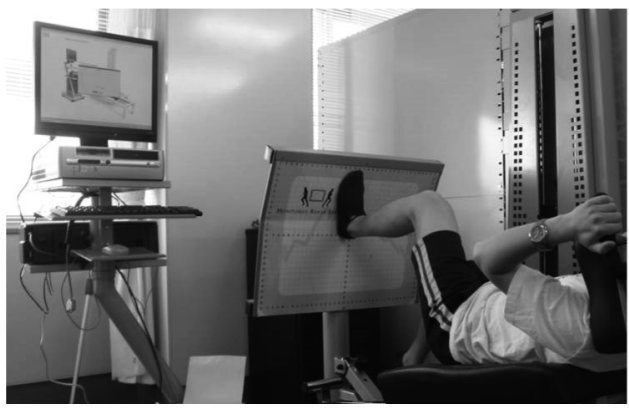

(a)

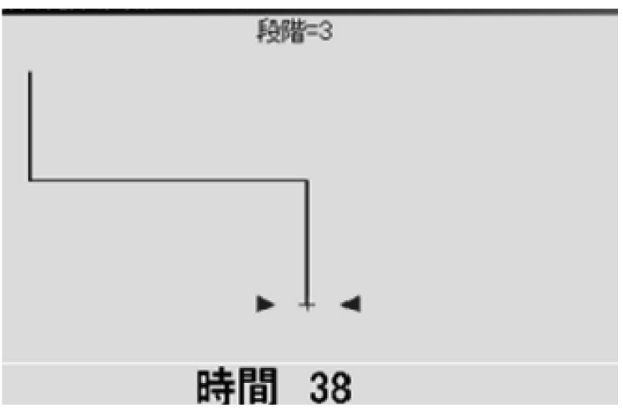

(b)

Fig.1. Evaluation of joint position sense using Monitorized Rehabilitation Systems-Functional Squat System

(a) Position of the subjects

(b) Computer screen during joint position sense measurement

of musculoskeletal systemic diseases were excluded. Prior to the study, subjects were informed of the purpose of the study and the general procedures to be undertaken. All subjects the provided their written informed consent as per our University's protocol. Approval for this study was obtained from the institutional review board of the Graduate School of Health Sciences, Hiroshima University.

\section{Methods}

JPS was evaluated using a Monitored Rehabilitation Systems Functional Squat System (MFSS). The MFSS is a software system capable of evaluating the position sense of the lower extremity throughout the concentric and eccentric phases of motion, during functional squat movements (Fig. 1a). The relative position of the lower extremity is displayed on a computer screen by a red "+" sign. The target joint position is displayed on the computer screen by a blue line. During the test, subjects use eccentric and concentric knee movements to move a corresponding red "+" sign into alignment with the blue line (Fig. 1b). Deviation is measured as the distance between the red "+" sign and the blue line. Following the completion of each test, the distance between the deviations recorded with and without visual input was evaluated as absolute error (AE). In addition, MFSS has been reported in the literature to be a valid and reliable method for the evaluation of joint proprioception ${ }^{11)}$.

The non-dominant leg of each study subject was measured. It was adopted as the test leg, because the majority of surgical limbs in anterior cruciate ligament reconstruction are non-dominant ${ }^{12}$. The dominant leg was defined as the leg usually used for kicking a soccer ball ${ }^{13)}$. In this study, all participants indicated their right leg was the dominant leg. The start position was fixed as the body posture in which the angles of the hip joint and knee joint were at $90^{\circ}$ flexion. JPS was measured under 4 separate active flexion conditions, with knee flexion values of $30^{\circ}$ and $60^{\circ}$, and joint loads of $5 \mathrm{~kg}$ and $20 \mathrm{~kg}$, with combinations of joint flexion and load chosen randomly. When subjects first attained the target angle, they were allowed to maintain and memorize the position of the joint, with visual aid, for 6 seconds. In the next step, subjects were returned to the original starting position of $90^{\circ}$ flexion. Once the predetermined time had passed, subjects were asked to reproduce the position without visual aid. After 6 seconds, data were recorded. Subjects were asked to reproduce joint position without visual aid at 3 time intervals: immediately, 5 minutes post-memorization, and 30 minutes post-memorization, . In order to unify measurement parameters, the subjects discussed their positions relative to the computer target symbols, with the examiner, during testing.

Data of the subjects were analyzed using the SPSS 12.0 statistics program under the Windows operating system. The Tukey-Kramer multiple method was adopted to compare the AE between the allotted test time intervals. Significance was accepted for values of $\mathrm{p}<0.05$.

\section{RESULTS}

The results indicate that $\mathrm{AE}$ gradually became greater with time. The immediate AE, 5-minute AE, and 30-minute $\mathrm{AE}$ are shown in Table 1. There was no significant difference in AE, dependent on knee flexion and load. However, the difference between the immediate $\mathrm{AE}$ and 30-minute AE was statistically significant $(p<0.05)$, except when knee flexion was at $60^{\circ}$ with a $5 \mathrm{~kg}$ load. There was no significant difference between the immediate AE and 5-minute $\mathrm{AE}$ under any of the conditions assigned. Additionally, there was no significant difference between the 5-minute $\mathrm{AE}$ and 30-minute $\mathrm{AE}$ under any of the conditions assigned.

\section{DISCUSSION}

Although a previous study indicated the presence of a positive correlation between JPS and quadriceps load strength $^{9)}$, the results of our present study do not show that load was a defining factor. This may be because the squatting position used in the present study did not rely solely on the quadriceps. Previous studies focused solely on the knee joint. In contrast, this experiment included the activity of other joints, such as the hip and ankle. Therefore, the tested JPS included JPS values of all the individual joints involved 
Table 1. The absolute error (AE) immediately, 5 minutes and 30 minutes post-memorization

\begin{tabular}{lccc}
\hline & Immediate AE $(\mathrm{mm})$ & 5-minute AE $(\mathrm{mm})$ & 30-minute AE $(\mathrm{mm})$ \\
\hline Knee flexion $30^{\circ}$, Load $5 \mathrm{~kg}$ & $10.4 \pm 7.9$ & $17.7 \pm 6.7$ & $29.3 \pm 10.5^{*}$ \\
Knee flexion $60^{\circ}$, Load $20 \mathrm{~kg}$ & $10.8 \pm 6.1$ & $22.0 \pm 10.6$ & $30.8 \pm 9.6^{*}$ \\
Knee flexion $30^{\circ}$, Load $20 \mathrm{~kg}$ & $9.3 \pm 8.2$ & $15.0 \pm 8.4$ & $24.5 \pm 19.2^{*}$ \\
Knee flexion $60^{\circ}$, Load $5 \mathrm{~kg}$ & $10.6 \pm 7.9$ & $18.2 \pm 8.6$ & $22.6 \pm 12.0$ \\
\hline
\end{tabular}

Values are mean \pm SD

*Significant difference between immediate AE and 30-minute AE $(\mathrm{p}<0.05)$.

the hip, ankle, and knee. This may explain the finding that the effects of different knee joint flexion angles on JPS were not statistically significant. Contrary to the original hypothesis of this study, joint angle and load demonstrated no influence on JPS or JPS memory.

In this study, we investigated the retention of JPS in memory with the passage of time, flexion angle, and joint/ muscular loading. JPS clearly became less accurate as AE increased with the passage of time. Differences in JPS between the immediate interval and 30-minute interval were statistically significant. The exception to this was when knee flexion was at $60^{\circ}$, under a load of $5 \mathrm{~kg}$. This may be because JPS is less sensitive under the condition of a greater knee flexion angle in the presence of reduced load. The results suggest that JPS memory may have been lost after 30 minutes. Moreover, no significant difference was found between the immediate AE and 5-minute AE for all the tasks. Thus, we conclude that JPS can be retained in memory for approximately 5 minutes. The results also suggest that JPS training should not involve intervals exceeding 30 minutes.

This study had certain limitations. A previous study reported that JPS of the knee is reduced by the inclusion of an attention-demanding task but not by experimentally induced pain ${ }^{14)}$. However, attention as a distraction cannot be practically measured, although it has a strong influence on JPS. The results may also be influenced by age because the JPS of older subjects has been shown to be poorer than that of younger subjects ${ }^{15)}$. In addition, the present study analyzed only the non-dominant leg. In the future, it may be beneficial to examine the differences in JPS memory between the non-dominant leg and the dominant leg.

\section{ACKNOWLEDGEMENTS}

We would like to thank the reviewers for providing helpful comments on this manuscript.

\section{REFERENCES}

1) Muaidi QI, Nicholson LL, Refshauge KM: Do elite athletes exhibit enhanced proprioceptive acuity, range and strength of knee rotation compared with non-athletes? Scand J Med Sci Sports, 2009, 19: 103-112. [Medline] [CrossRef]

2) Hurley MV: The effects of joint damage on muscle function, proprioception and rehabilitation. Man Ther, 1997, 2: 11-17. [Medline] [CrossRef]

3) Baker V, Bennell K, Stillman B, et al.: Abnormal knee joint position sense in individuals with patellofemoral pain syndrome. J Orthop Res, 2002, 20: 208-214. [Medline] [CrossRef]

4) Beard DJ, Kybeard PJ, Fergusson CM, et al.: Proprioception after rupture of the anterior cruciate ligament. J Bone Joint Surg, 1993, 75: 311-315. [Medline]

5) Hopper DM, Creagh MJ, Formby PA, et al.: Functional measurement of knee JPS after anterior cruciate ligament reconstruction. Arch Phys Med Rehabil, 2003, 84: 868-872. [Medline] [CrossRef]

6) Borsa PA, Lephart SM, Irrgang JJ, et al.: The effects of joint position and direction of joint motion on proprioceptive sensibility in anterior cruciate ligament-deficient athletes. Am J Sports Med, 1997, 25: 336-340. [Medline] [CrossRef]

7) Clark FJ, Burgess RC, Chapin JW, et al.: Role of intramuscular receptors in the awareness of limb position. J Neurophysiol, 1985, 54: 1529-1540. [Medline]

8) Kai S, Nara I: Relationships among jump motion control ability, knee JPS, and adjusting muscle contraction in healthy subjects. J Phys Ther Sci, 2004, 16: 119-127. [CrossRef]

9) Zhou MW, Gu L, Chen YP, et al.: Factors affecting proprioceptive recovery after anterior cruciate ligament reconstruction. Chin Med J, 2008, 121: 2224-2228. [Medline]

10) Bouet V, Gahery Y: Muscular exercise improves knee position sense in humans. Neuroscience letters, 2000, 289: 143-146.

11) Maffiuletti NA, Bizzini M, Schatt $S$, et al.: A multi-joint lower-limb tracking-trajectory test for the assessment of motor coordination. Neurosci Lett, 2005, 384: 106-111.

12) Bjornaraa J, Di Fabio RP: Knee kinematics following ACL reconstruction in females; the effect of vision on performance during a cutting task. Int J Sports Phys Ther, 2011, 6: 271-284. [Medline]

13) Greenberger HB, Paterno MV: Relationship of knee extensor strength and hopping test performance in the assessment of lower extremity function. JOSPT, 1995, 22: 202-206. [Medline] [CrossRef]

14) Bennell K, Wee E, Crossley K, et al.: Effects of experimentally-induced anterior knee pain on knee joint position sense in healthy individuals. $\mathrm{J}$ Orthop Res, 2005, 23: 46-53. [Medline] [CrossRef]

15) Barrett DS: Proprioception and function after anterior cruciate reconstruction. J Bone Joint Surg Br, 1991, 73: 833-837. [Medline] 